\title{
DESIGNING AND SELECTION OF RELIABILITY BASED SAMPLING PLANS
}

\section{JEMMY JOYCE \& K. REBBECA JEBASEELI EDNA}

Department of Mathematics, Karunya University, Coimbatore, Tamil Nadu, India

\begin{abstract}
Reliability of engineering system is very much essential in production industries. However accurate Reliability of a system or device is tedious if the number of components or items is large. But the decision has to be made whether to accept or reject a batch of items based on the reliability of the components and hence Reliability-based Sampling Plans indexed by operating reliability rate at the deflection point (RSP-RR) are developed using Exponentiated Loglogistic model. Tables and illustration are also provided for easy selection of the plan. The minimum sample size required for testing the sample units can be obtained using RSP-RR sampling plans.
\end{abstract}

KEYWORDS: Operating Reliability Rate, Deflection Point \& Exponentiated Log-Logistic

Received: Apr 17, 2018; Accepted: May 08, 2018; Published: Jul 06, 2018; Paper Id.: IJMPERDAUG201836

\section{INTRODUCTION}

The RSP-RR sampling plans are designed in such a way that they are more economical with respect to less test equipment, test monitoring and data recordings. The reliability, corresponding to the deflection point of the operating characteristic curve is denoted by $p_{m}$. Also, the point $p_{T}$, at which the tangent at deflection point to the operating characteristic curve cuts the reliability axis is taken into account to measure the reliability rate of the sampling plan.

\section{LITERATURE REVIEW}

DevaArul(2002) has developed Mixed Reliability Sampling plans and Maximum Acquired Reliability Sampling plans. The log-logistic distribution has been studied in detail by Shah and Dave (1963) and Tadikermalla and Johnson(1982). Survival models based on the logistic and log-logistic distributions are given by O'Quigley and Struthers(1982). The other contributions are Ragab and Green(1984) Balakrishnan and Malik (1987), Kantam etal(2001) have developed sampling plans based on the log-logistic model. Kantam and Rosiah(1988) have developed truncated life tests for half logistic distribution. Schneider(1989) studied failure censored variable sampling plan for the lognormal and Weibull model. Fertig and Mann(1980) have developed life test sampling plans for the extreme value and Weibull distributions. Hosono etal(1981) designed sampling plans for twoparameter exponential family. Reliability test plans for Exponential log-logistic distribution is given by K. Rosiah (2006).

\section{DESIGNING THE RELIABILITY SAMPLING PLAN}

The operating charactering function, where $p_{m}$ is reliability is given $\mathrm{b}$ 


$$
P_{a}\left(p_{m}\right)=1-\sum_{j=0}^{s} \frac{e^{-n p_{m}}\left(n p_{m}\right)^{s}}{s !}
$$

Differentiating with respect to $\mathrm{p}_{\mathrm{m}}$ twice and equating to zero, we get

$$
\begin{aligned}
& \frac{d\left(P_{a}\left(p_{m}\right)\right)}{d p_{m}}=\frac{n\left(n p_{m}\right)^{s} e^{-n p_{m}}}{s !} \\
& \frac{d^{2}\left(P_{a}\left(p_{m}\right)\right)}{d p_{m}}=\frac{n\left(n p_{m}\right)^{s} e^{-n p_{m}}}{s !} \frac{\left(s-n p_{m}\right)}{p_{m}}=0
\end{aligned}
$$

The maximum reliability in the lot is given by, $p_{m}=\frac{s}{n}$

In this plan $S$ is the number of survival required for the acceptance of the lot from the sample of size $\mathrm{n}$.

\section{THEOREM1}

The tangent to the power curve at the deflection point touches the reliability axis at $p_{T}=\frac{s}{n}-\frac{s !}{n s^{s} e^{-s}}\left(1-\sum_{j=0}^{s} \frac{e^{-s} s^{j}}{j !}\right)$

\section{Proof}

Equation of tangent passing through $\left(\frac{s}{n}, 1-\sum_{j=0}^{s} \frac{e^{-n p_{m}}\left(n p_{m}\right)^{j}}{j !}\right)$ with slope $\frac{n\left(n p_{m}\right)^{s} e^{-n p_{m}}}{s !}$ is given by the equation

$$
P_{a}\left(p_{t}\right)-\left(1-\sum_{j=0}^{s} \frac{e^{-n p_{m}}\left(n p_{m}\right)^{j}}{j !}\right)=\frac{n\left(n p_{m}\right)^{s} e^{-n p_{m}}}{s !}\left(p_{t}-\frac{s}{n}\right)
$$

The root of the above equation is by equating $P_{a}\left(p_{t}\right)=0$ and the root is denoted by $p_{T}$

$$
\begin{gathered}
p_{T}-\frac{s}{n}=-\frac{s !}{n\left(n p_{m}\right)^{s} e^{-n p_{m}}}\left(1-\sum_{j=0}^{s} \frac{e^{-n p_{m}}\left(n p_{m}\right)^{j}}{j !}\right) \\
p_{T}=\frac{s}{n}-\frac{s !}{n\left(n p_{m}\right)^{s} e^{-n p_{m}}}\left(1-\sum_{j=0}^{s} \frac{e^{-n p_{m}}\left(n p_{m}\right)^{j}}{j !}\right)
\end{gathered}
$$

At the deflection point, $n p_{m}=S$

Therefore, the point at which the tangent touches the reliability axis is given by

$$
p_{T}=\frac{s}{n}-\frac{s !}{n s^{s} e^{-s}}\left(1-\sum_{j=0}^{s} \frac{e^{-s} s^{j}}{j !}\right)
$$


Let the operating reliability rate be $z=\frac{p_{T}}{p_{m}}$

$$
z=1-\frac{s !}{s^{s+1}}\left(e^{s}-\sum_{j=0}^{s} \frac{s^{j}}{j !}\right)
$$

This $\mathrm{z}$ is purely function of ' $\mathrm{s}$ '.

\section{ALGORITHM}

Procedure for sentencing a lot or system

Step 1: For the given operating ratio ' $z$ ', find the values of number of survival units 's' from table one.

Step 2: From table 2, find the value of $n$. Take a random sample of size n, and test them into life test for specified time t (type I censoring)

Step 3: Count the number of specimens successful in the test. Let it be ' $\mathrm{x}$ '.

Step 4: If $x \geq s$ then accept the lot.

Step 5: If $x<s$ then reject the lot.

Table 1: The Values of Number of Survival Units ' $\mathrm{s}$ ' and the Operating Ratio $\mathrm{z}$ are Tabulated

\begin{tabular}{|c|c|c|c|c|c|c|c|c|c|c|}
\hline $\mathbf{s}$ & $\mathbf{1}$ & $\mathbf{2}$ & $\mathbf{3}$ & $\mathbf{4}$ & $\mathbf{5}$ & $\mathbf{6}$ & $\mathbf{7}$ & $\mathbf{8}$ & $\mathbf{9}$ & $\mathbf{1 0}$ \\
\hline $\mathrm{z}$ & .2817 & .4027 & .4750 & .5155 & .5621 & .5919 & .6150 & .6360 & .6520 & .6670 \\
\hline
\end{tabular}

Table: 2 The Values of Sample size for $\theta=2$, Given the Test Time ' $t$ ', Average life $\sigma_{0}$ and Number of Successful Units 's' using Exponentiated Log-Logistic Distribution.

\begin{tabular}{|c|c|c|c|c|c|c|c|c|c|c|c|c|}
\hline \multirow[t]{2}{*}{$t / \sigma_{0}$} & \multirow{2}{*}{$F\left(t, \sigma_{0}\right)$} & \multirow{2}{*}{$p_{m}$} & \multicolumn{10}{|c|}{ Number of Successful Units } \\
\hline & & & 1 & 2 & 3 & 4 & 5 & 6 & 7 & 8 & 9 & 10 \\
\hline .63 & 0.079 & .921 & 1 & 2 & 2 & 4 & 5 & 7 & 8 & 9 & 10 & 11 \\
\hline .94 & 0.221 & .779 & 1 & 3 & 4 & 5 & 6 & 8 & 9 & 10 & 12 & 13 \\
\hline 1.26 & 0.375 & .625 & 2 & 3 & 5 & 6 & 8 & 10 & 11 & 13 & 14 & 16 \\
\hline 1.57 & 0.506 & .494 & 2 & 4 & 6 & 8 & 10 & 12 & 14 & 16 & 18 & 20 \\
\hline 2.36 & 0.717 & .283 & 4 & 7 & 11 & 14 & 18 & 21 & 25 & 28 & 32 & 35 \\
\hline 3.14 & 0.824 & .176 & 6 & 11 & 17 & 23 & 28 & 34 & 40 & 45 & 51 & 57 \\
\hline 3.93 & 0.882 & .118 & 8 & 17 & 25 & 34 & 42 & 51 & 59 & 68 & 76 & 85 \\
\hline 4.71 & 0.906 & .094 & 11 & 21 & 32 & 43 & 53 & 64 & 74 & 85 & 96 & 106 \\
\hline
\end{tabular}

By using table (2) one can readily obtain the sample size required for testing sample units. From the table, it is clear that, if the sample size increases then the reliability decreases.

\section{EXAMPLE}

Determine the reliability based sampling plan indexed with a reliability rate of $z=.39$ when average life of a product is $100 \mathrm{hrs}$, test time is $94 \mathrm{hrs}, \theta=2$. 
Solution: $t / \sigma_{0}=.94$, Using table $1, \mathrm{~s}=2$, Using table $2, \mathrm{n}=3$.

Procedure for sentencing the lot

- $\quad$ Take a random sample of size 3 and put them into life tests for 94 hours

- Count the number of successful units in the test.

- If the number of successful units is less than 3 , then reject the lot.

- If the number of successful is greater than or equal to 3 then accept the lot.

\section{CONCLUSIONS}

In this paper, Reliability-based Sampling Plans indexed by operating reliability rate at the deflection point are developed using Exponentiated Log-logistic model. One can readily obtain the sample size required for testing sampling units. The sample size is less, and hence the plan is economical. Table 2 shows that, if the sample size increases then the reliability decreases, tables and illustration are also provided.

\section{REFERENCES}

1. DEVAARUL, S (2002), “Certain Studies relating to Mixed Sampling plans and Reliability based Sampling Plans”, Ph.D., Thesis, Department of Statistics, Bharathiar University, Coimbatore, Tamilnadu, India

2. DEVAARUL,S(2003), “Maximumum Acquired Reliability Sampling (MARS) plan”, Far East Journal of Theoretical Statistics, 10, No.1, pp $25-32$.

3. KANTAM R.R.L, ROSIAH K, \& G.SRINIVASA RAO (2001), "Acceptance sampling based on life tests: loglogistic model", Journal of Applied Statistics, Vol. 28, No.1, pp 121

4. RAGAB,A. \& GREEN,J.(1984), "On order statistics from loglogistic distribution and their properties", Communications in Statistics - Theory and Methods, 13, pp.2713-2724

5. BALAKRISHNAN, N. \& MALIK, H.K.(1961), "Best linear unbiased estimation of location and scale parameters of the Loglogistic distribution”, Communications in Statistics - Theory and Methods, 16, pp.3477-3495

6. CAO, THANH BINH, and SLAWOMIR KEDZIORA. "New methodology for designing direct-laser-sintered motorcycle frame based on combination of topology optimization and lattice implementation." (2017).

7. O'QUIGLEY,J. \& STRUTHERS, L.(1982), “Survival models based upon the logistic and log-logistic distribution” Computer programmes in Biomedicine, 15, pp $3-12$

8. SHAH, B.K. \& DAVE, P.H. (1963), “A note on log logistic distribution”, Journal of Mathematical Sciences of University of Baroda, 12, pp. 21-22

9. TADIKAMALLA, P.R. \& JOHNSON, N.L.(1982), "Systems of frequency curves generated by the Transformation of logistic variables", Biometrika, 69, pp. $461-465$

10. NAGHDI, R., et al. "Designing of forest road network based on technical and economical considerations using GISAHP." International Journal of Applied and Natural Sciences 1.2 (2012): 39-44.

11. FERTIG,K.W. \& MANN,N.R.(1980), “Life test sampling plans for two parameter weibull populations, Technometrics, 22, pp.165-177 
12. HOSONA,Y., OHTA, H. \& KASE,S.(1981), “ Design of single sampling plans for doubly exponential Characteristics, Frontiers in statistical quality control, pp. $94-112$

13. ROSIAH.K.,KANTAM.R.L.,SANTHOSH KUMAR(2006), "Reliability test plans for Exponentiated loglogistic distribution", Economic Quality Control,Vol.21,pp279-289. 
